\title{
Docking of FDA Approved Drugs Targeting NSP-16, N- Protein and Main Protease of SARS-CoV-2 as Dual Inhibitors
}

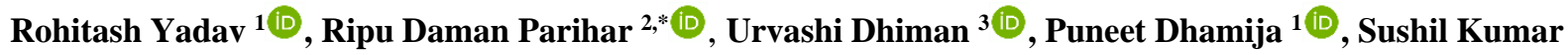 \\ Upadhyay $^{4}$ (D), Mohammed Imran ${ }^{5}$ (D), Santosh Kumar Behera ${ }^{6}$ (D), T.S. Keshava Prasad ${ }^{6}$ (D) \\ Department of Pharmacology, All India Institute of Medical Sciences, Rishikesh, India \\ Department of Zoology, Central University of Jammu, Jammu \& Kashmir, India \\ Department of Zoology, DAV University, Jalandhar, India \\ 4 Department of Biotechnology, Maharishi Markandeshwar (Deemed to be University), Mullana-Ambala-133207 \\ (Haryana), India \\ 5 Department of Pharmacology, College of Medicine, Shaqra University, Kingdom of Saudi Arabia \\ 6 Center for Systems Biology and Molecular Medicine, Yenepoya Research Centre,Yenepoya (Deemed to be University), \\ Mangalore-575018, India \\ * Correspondence: ripuparihar89@gmail.com;
}

Scopus Author ID 56692536400

Received: 2.09.2020; Revised: 19.09.2020; Accepted: 20.09.2020; Published: 22.09.2020

Abstract: At present world is lurching under the spread of new SARS-CoV-2 infection. The treatment is still elusive despite the relentless effort by the scientists against various viral structures. Whereas the 3-Chymotrypsin-like proteases cleave polyproteins and structural proteins help in viral replication. At the same time, non-structural proteins stimulate mRNA cap methylation to evade the immune response. The present study aims to identify novel dual inhibitor compounds with potential hits simultaneously against any of these three targets, including 3C-like proteases, N-protein, and NSP16 through virtual screening, molecular docking approach, and molecular dynamics. Such dual inhibitors may provide the necessary treatment to alleviate the current pandemic. We screened 265 FDA approved infectious disease drugs against three types of Covid-19 targets, i.e., 3C-like proteinase (6w63), N-protein (6vyo), and Non-structural protein $16(6 \mathrm{w} 4 \mathrm{~h})$ using a computer-assisted drug repurposing approach in this study. The Schrodinger suite 2019 is employed for high throughput screening, molecular docking, and binding free energy through the Glide module. We sorted 27 drugs, out of which the best common three drugs were suggested based on their virtual statistics parameters. We found three drugs that belonged to two main categories as dual inhibitors. The Plazomicin (Aminoglycoside) and Cefiderocol (Cephalosporins) are an antibiotic group of drugs, and the Vanganciclovir is antiviral. The molecular dynamics simulation studies over 30000ps for Plazomicin against NSP16 was conducted based on their promising docking scores profile. The RMSD parameter remained stable at $2.5 \AA$ for ligands for 30000 ps. Thus these three compounds can be validated as a SARS-CoV-2 therapy through clinical trials.

Keywords: SARS-CoV-2; dual inhibitors; NSP-16; main protease; COVID-19.

Abbreviations: CoV: Coronavirus; MERS: Middle East Respiratory Syndrome; SARS: Severe Acute Respiratory Syndrome; MD: Molecular Dynamics; COVID-19: Coronavirus Disease 2019; RNA: Ribonucleic acid; PDB: Protein Data Bank; HTVS: High throughput virtual screening; FDA: Food and Drug Administration; WHO: World Health Organization; NSP: Non-Structural Proteins; 3CP: 3' Chymotrypsin-like protease.

(C) 2020 by the authors. This article is an open-access article distributed under the terms and conditions of the Creative Commons Attribution (CC BY) license (https://creativecommons.org/licenses/by/4.0/). 


\section{Introduction}

The novel coronavirus ( $\mathrm{CoV})$ designated as SARS-CoV-2 has led to the latest global outbreak [1-2]. It has the positive single-stranded RNA housed in a pleomorphic or spherical shape having glycoproteins on the outer surface, which are club-shaped in appearance [3-4]. Initially, it has emerged from the zoonotic sources in Wuhan city of China, but it is responsible for the human to human transmission now causing illness similar to ARDS (Acute Respiratory Distress Syndrome) called COVID-19 [5-6]. This outbreak has affected the entire world, and WHO has declared it a pandemic. Consequently, there are considerable efforts to understand the pathogenesis, viral properties, and potential drugs to control this virus [7]. However, the treatment still remains elusive and requires further study to develop new strategies and treatments. It is imperative to understand the properties of the virus to decipher a new treatment. SARS-CoV-2 shares $89.1 \%$ nucleotide similarity with earlier severe acute respiratory syndrome coronavirus (SARS-CoV) [8]. It encodes twelve putative open reading frames, which are responsible for the production of structural as well as non-structural proteins [9]. CoV-2 possess four structural proteins, i.e., trimeric spike ( $\mathrm{S}$ glycoprotein) consists of $\mathrm{S} 1$ and $\mathrm{S} 2$ subunits which are responsible for attachment, fusion, and entry; M protein (matrix protein); E protein (envelope protein); and N protein (nucleocapsid protein) for viral RNA synthesis and its replication along with other proteases [10-11]. The $\mathrm{N}$-protein is the least variable and highly conserved structure among the structural proteins. It has three domains consisting of NTD (N-terminal domain), CTD (C-Terminal domain), and a central serine/Arginine rich linker domain. It's binding with RNA genome forms ribonucleoprotein complexes, which are necessary for virion core and RNA synthesis [12]. The overall amino acid folds are divided just like palms and fingers in the hands, such as in 6vyo and 6m3m [13-14].

There are two types of proteases in The SARS-CoV-2, which are also highly conserved structures. The Plpro (papain-like) and 3CLpro (3-Chymotrypsin-like proteases), which belong to the cysteine protease family in contrast to HIV protease, which belongs to the aspartic protease family [15-16]. The 3CLpro, cleaves the C-terminus at 11 sites of the polyproteins under replication. They recognize [ILMVF]-Q-|-[SGACN] a specific core sequence and bind with ADRP (AD-ribose-1"-phosphate) as well. Thus a drug based on its inhibitions may prove a worthy search [17]. Moreover, as the outbreak has progressed, there is growing knowledge of the conserved non-structural polyproteins of this virus, such as 2'O-methyl-transferase [18]. One of the non-structural proteins (NSP) is NSP16. This protein is responsible for the 2'O methylation capping of mRNA (virus), which distinguishes between the agent and the host, and it is one of the immunological virulence determinants [19]. There is a variety of other highly conserved NSP (NSP13, NSP14, and NSP10/ASP16 complex) in the CoV, which caps the RNA of the virus to prevent its recognition by the host immunological mechanism. The role of the non-structural proteins like NSP10 is to stimulate NSP16 2'-O-methyltransferase and NSP14 3'-5' exoribonuclease and activities for mRNAs cap methylation by forming NSP10/NSP16 hetero-oligomeric complexes with the help of 2'-O-ribose methyltransferase (NSP16) to evade the host immune system [20].

NSP10/NSP16 or RNA methyltransferase or MTase are critical proteins that participate in SARS CoV-2 infection. Recent reports on the mapping of its atomic structure that nsp10 and nsp16 claims that modify viral genetic material to appear like host cell RNA in humans [21]. Nsp10/nsp16 remains bounded together to make a functional protein and is indispensable for viral replication [22]. The virus remains shielded by the immune cells of the host and gets 
enough time to multiply and get established. Additionally, SARS-CoV-2 RNAs have 50 ends caps to impede its degradation with 50 exoribonucleases to ensure efficient translation and escape recognition by the innate immune system of the host cell [23-24]; SARS-CoV-2 20-OMTase (20-O-methyltransferase) NSP16 protein is an RNA enzyme plays a role in cap modification and do not have enzymatic activity. This NSP16 gets activated by NSP10, which further interacts with NSP16 and show selective 20-O-MTase activity on RNA caps (N7methyl guanine). The methylation process works in an ordered sequence whereby RNA cap N7-MTase, NSP14 (guanine-N7-methyltransferase) mediated N7-guanine methylation followed by NSP16/NSP10-catalyzed RNA 20-O-methylation [25]. The NSP16 2'O-MTase activity shows a significant role in the evasion of innate immunity, and the deficiency in 2'OMTase could increase IFN responses against the viral infection [26]. The cap structure is required for nuclear export, translation, efficient splicing, and eukaryotic mRNA stability. Utmost viruses use host translational machinery; however, there are certain exceptions like picornaviruses and hepatitis $\mathrm{C}$. To outwit the capping issue, these viruses use IRES (internal ribosome entry site) for their mRNA translation. Eukaryotic viruses evolved various strategies for mRNA capping, such as cap-dependent mechanisms [27].

However, it has been seen that NSP16 has a greater role in capping the CoV mRNA. Either alone as NSP16 or in complex with NSP10, It is an S-adenosylmethionine (SAM)dependent nucleoside-2'O-methyltransferase that forms the cap-1 structure to prevent its recognition from the host. The structural domains of amino acid sequences belonging to NSP16/NSP10 in SARS-CoV-1, MERS-CoV, and SARS-CoV-2 are highly conserved [28]. The researchers believe if a drug can be developed to inhibit NSP10/NSP16, the immune system should be able to detect the virus and eradicate it faster. Therefore, the drugs or treatment targeting NSP16 may prove effective. A smart way to find the solution is to repurpose the already FDA approved drugs for development in SARS-CoV-2 infections [29]. This costeffective approach predicts new biological roles to already approved existing drugs advocating control of existing diseases through quick alternative therapies. In the present study, we are reporting candidates to hit the NSP16 and 3CLpro targets simultaneously so that there is no viral replication and the immune system can successfully detect the virus eradicate it quickly.

\section{Materials and Methods}

\subsection{Target selection\& molecular library preparation.}

The present study was designed with the objective of constructing dual inhibitors of SARS-CoV-2. We selected two targets for our study, i.e., 3C-like proteases (3CP), NSP16 (Non-structural protein) with their PDB ID 6w63, and 6w4h, respectively. Both types of selected protein crystal structures were having high resolution and were conservative in nature. The three-dimensional structure of these proteins was obtained from PDB ( Protein Data Bank) (https://www.rcsb.org/). The 2-dimensional structures of ligands were downloaded from open chemistry databases PubChem (https://pubchem.ncbi.nlm.nih.gov/). Thus a total of 265 FDA approved drugs of infectious disease were selected for this study. Fig. 1 depicts the computational screening outflow of the study.

\subsection{Proteins and ligand preparation.}

For the preparation of downloaded protein structures from (PDB) Protein Data Bank and RCSB were subjected to Schrodinger's Protein Preparation Wizard. Processing involves 
the addition of the hydrogen atoms and removal of water molecules by creating het states at EpikPh $7 \pm 2$ along with the formation of disulfide bonds and metal atoms form bonds with zeroorder. The missing atoms were added using the Schrodinger Prime module, the bond orders were conveyed, and the methionine was created from selenomethionine. N-terminal hydrogen bonding network was optimized to renovation by the overlying hydrogens, and energy was minimized by using the OPLS3e force field. Ligands preparation was done using the Ligprep module of the Schrödinger suite with suitable parameters such as ring conformation, 2D to 3D conversion, tautomers, optimization, ionization states $(\mathrm{pH} 7.0)$, and determination of promoters; along with partial atomic charges by using OPLS3e force field.

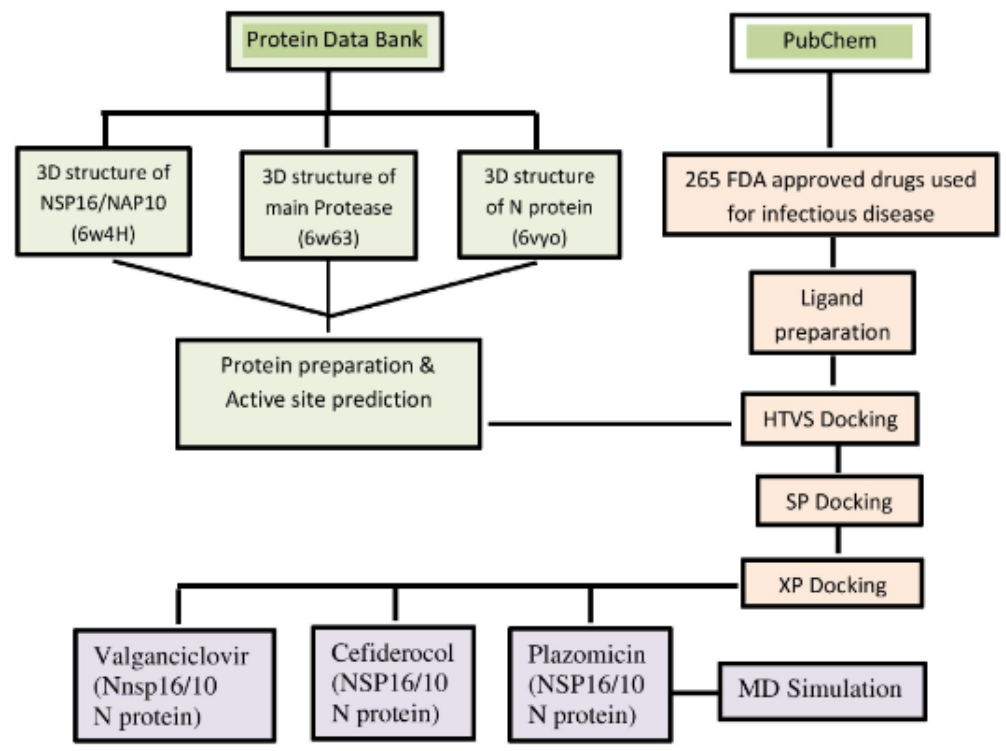

Figure 1. Schematic presentation of the work plan of the current study.

\subsection{Active site prediction \& receptor grid generation.}

A suitable active site for the binding of ligand was recognized by the virtual screening process. The native ligand-binding site of the receptor was selected for grid box generation. The glide module in Maestro 12.0 Schrodinger suite was used for receptor grid generation by the native ligand of the proteins. The size of the grid box was centroid of native ligands of the protein receptors, and the docked ligands were similar in size to the native ligand. The atoms of protein were fixed within the default parameters of the radii of Vander Waal's scaling factor of $1 \AA$ with partial charge cut-off of $0.25 \AA$ using OPLS3e force field. The dimensions of the grid box were set up for outer and internal at $x=20 \AA, y=20 \AA, z=20 \AA$ and $x=10 \AA, y=10 \AA$, $\mathrm{z}=10 \AA$, respectively with a grid space of $1 \AA$.

\subsection{Molecular docking.}

Chemical compounds for performing High Throughput Virtual Screening (HTVS) against a set of target proteins (PDB ID: 6w63) were retrieved from the PubChem database. HTVS with flexible docking was performed on Schrodinger's maestro 12.0 model using 265 prepared ligands against the receptor grid. After HTVS, 200 ligands were filtered out by using Standard Precision (SP) using the ligand-docking process. Out of 200 ligands, 100 ligands were found to have the best conformation with the highest docking score, which were further sorted by Extra Precision (XP) with Flexible docking. These 100 ligands were docked with other 
target proteins (PDB ID: 6w4h). Finally, the best ranking top nine compounds were selected using criteria of docking scores.

\subsection{Calculation of binding free energies using the prime MM-GBSA approach.}

The binding free energies of identified ligand molecules to its receptor complex were analyzed by using the prime MM-GBSA (Molecular Mechanics Generalized Born Surface Area) module of the Schrodinger suite along with the OPLS3e force field. The prime MMGBSA approach relied on the docking complex and is used to calculate the $\Delta \mathrm{G}$ bind of each ligand. MM-GBSA approach is used as a rescoring function to prioritize the lead inhibitors. Values of binding free energies obtained from MM/GBSA calculations were considered along with the docking score to optimize identified drug molecules.

\subsection{Molecular dynamics simulations.}

The MDS of the ligand and NSP16 protein interactions were done to analyze the complex stability and correlation of structural aspects to the functional relevance. It reveals the strength, pattern, dynamics, conformational changes, and intermolecular interactions of the macromolecules. The MDS was done for 30000ps using the AMBER 18 software program. The study determined the RMSD and binding free energies of the complex. The established protocols were followed for the addition of sodium and chloride ions in the TIP3P rectangular box for neutralization of the system. The edge of the box was kept at $10 \AA$ away from the atoms of the protein. The binding pockets were simulated by the gaff force field. The system was gradually heated to $300 \mathrm{~K}$ temperature at NPT conditions, including 1 atm pressure. It was through 50ps subsequent to the 50ps density equilibrium. The solvent minimization was achieved by counterions, freezing the proteins, and removing the adverse contacts. The MD trajectories for every $5 \mathrm{~ns}$ and binding free energy calculations were done by inbuilt Amber tools.

\section{Results and Discussion}

The drug repurposing has become a boon for mankind in recent years. It proved very helpful in discovering the new inhibitory potentials of FDA approved drugs against a variety of targets. We have done the re-profiling of existing drugs against multiple targets such as main protease, N-protein, and one of the non-structural proteins (NSP16) of SARS-CoV-2 in this piece of work. The possibility of finding treatment for highly conserved NSP16 protein $(6 \mathrm{w} 4 \mathrm{H})$, Main protease (6w63), and N-protein (6vyo) was explored in this study for their therapeutic potential.

\subsection{Protein structure reliability.}

PROCHECK computational tools were used for determining quality, as well as the reliability of the three-dimensional structures of the targeted proteins. From this, Ramachandran plot was obtained, which helped in viewing the distribution of torsion angles in a protein structure. The plot also displayed allowed and the disallowed regions with regards to backbone dihedrals of protein residues. The above $90 \%$ score of most favored regions accounts for the good quality of the model. The Ramachandran plot (Fig. 2.) of 6w63, 6w4h, and 6vyo protein structures reflected that the residues falls within the most favored region in $99.7 \%$, $100 \%$ and $100 \%$ cases respectively (Table 1). In the red region, steric interactions are lowest, 
which indicates that the 3D structure is reliable. Steric interactions were minimum were due to the presence of forbidden psi and phi angles, thus narrating the worth of stereochemical quality of the three-dimensional protein structure.

Table 1. Ramachandran plot statistics showing favored regions in different targets.

\begin{tabular}{l|c|c|c|c|c|c}
\multirow{2}{*}{ Properties } & \multicolumn{2}{|c|}{$\mathbf{6 w 6 3}$} & \multicolumn{2}{c|}{$\mathbf{6 w} \mathbf{4}$} & \multicolumn{2}{c}{$\mathbf{6 v y o}$} \\
\cline { 2 - 7 } & Residues & $\mathbf{\%}$ & Residues & $\mathbf{\%}$ & Residues & \% \\
\hline The Most favored regions & 242 & 91.7 & 324 & 89.3 & 358 & 92.5 \\
\hline Additional allowed regions & 19 & 7.2 & 36 & 9.9 & 29 & 7.5 \\
\hline Generously allowed regions & 2 & 0.8 & 3 & 0.8 & 0 & 0.0 \\
\hline Disallowed regions & 1 & 0.4 & 0 & 0.0 & 0 & 0.0 \\
\hline $\begin{array}{l}\text { The End residues (excluding Glycine } \\
\text { and Proline) }\end{array}$ & 2 & & 32 & & 8 & \\
\hline Proline & 13 & & 16 & & 64 & \\
\hline Glycine & 26 & & 4 & & 40 & \\
\hline Total number of residues & 305 & 100 & 415 & 100 & 499 & 100
\end{tabular}
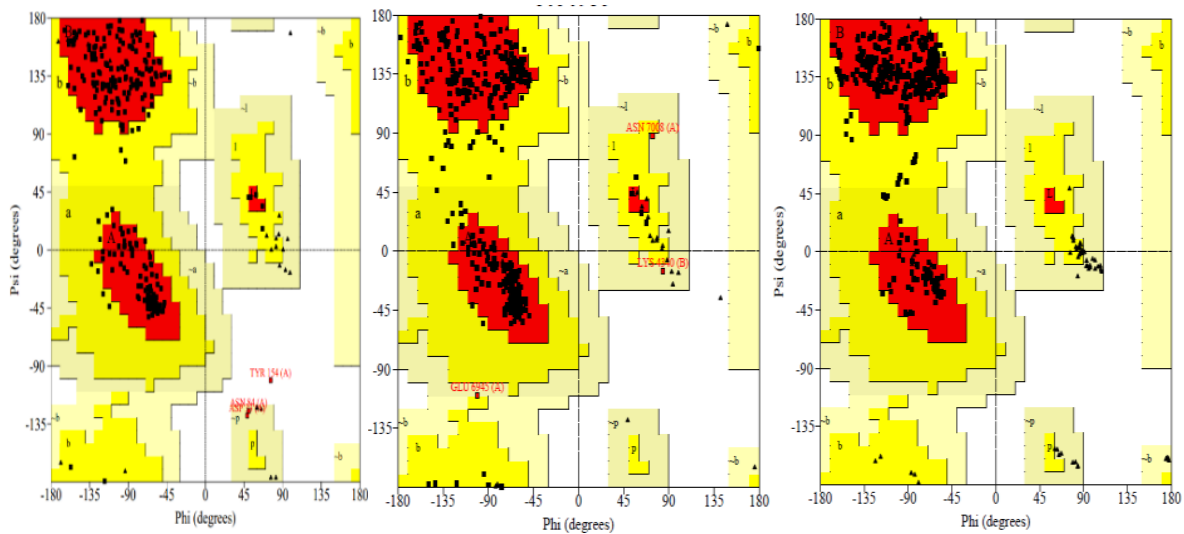

Figure 2. Ramachandran plots of different structures of novel SARS-CoV-2 virus proteins describe the stereochemically favored and disallowed regions of the residues.

\subsection{Binding site prediction and grid generation.}

Identification of residues at active site and location of the target structures help in designing potent drug molecules via protein inhibition at its binding site. Active sites of various protein structures were identified similar to native ligand molecules of the protein. The Site map measures size, docking score \& active side residues for docking study as presented in Table 2. In virtual screening during docking, the ligand molecules interact with binding sites of the protein.

Table 2. Active site residues, D-score, size, and site score of 6w63, 6w4h \& 6vyo predicted by Schrodinger's sitemap tools.

\begin{tabular}{|c|c|c|c|c|}
\hline PDB ID & D-Score & Size & $\begin{array}{l}\text { Site } \\
\text { Score }\end{array}$ & Residues \\
\hline $6 w 63$ & 1.066 & 120 & 1.02 & $\begin{array}{l}\text { Chain A: 24THR, 25THR, 26THR, 27LEU, 41HIE, 44CYS, 45THR, } \\
\text { 46SER, 49MET, 52PRO, 54TYR, 140PHE, 141LEU, 142ASN, 143GLY, } \\
\text { 144SER, 145CYS, 163HIE, 164HIE, 165MET, 166GLU, 167LEU, } \\
\text { 168PRO, 172HIE, 187ASP, 188ARG, 189GLN, 190THR, 192GLN }\end{array}$ \\
\hline $6 \mathrm{w} 4 \mathrm{~h}$ & 0.899 & 113 & 1.03 & $\begin{array}{l}\text { Chain A: 6841ASN, 6844LYS, 6845TYR, 6867HIS, 6868PHE, 6869GLY, } \\
\text { 6870ALA, 6871GLY, 6872SER, 6874LYS, 6947PHE, 6968LYS, } \\
\text { 6878PRO, 6879GLY, 6880THR, 6896SER, 6897ASP, 6898LEU, } \\
\text { 6899ASN, 6911GLY, 6912ASP, 6913CYS, 6928ASP, 6929MET, } \\
\text { 6930TYR }\end{array}$ \\
\hline 6vyo & 1.045 & 183 & 1.039 & $\begin{array}{l}\text { Chain C- 50ALA; 51SER; 53PHE; 54THR; 55ALA; 56LEU; 57THR; } \\
\text { 59HIP; 92ARG; 107ARG; 109TYR; 149ARG; 156ALA; 157ILE; 158VAL } \\
\text { Chain D- 53TRP; 73PRO; 74ILE; 75ASN; 76THR; 77ASN; 78SER; } \\
\text { 82ASP; 145HIE; 146ILE; 147GLY; 148THR; 149ARG; 150ASN; 153ASN; } \\
\text { 154ASN; 155ALA; 157ILE; 158VAL;159LEU; 160GLN }\end{array}$ \\
\hline
\end{tabular}


3.3. Molecular docking and ligand optimization using hydrogen bond interactions and binding free energies [MM-GBS].

The selection of most suitable drug compounds acquired from molecular docking \& virtual screening of the PubChem dataset was obtained by analyzing respective scoring functions and values of their (MM/GBSA) binding free energies. Molecules with top-scores from Table 3 were prioritized based on the docking scores. These molecules were further ranked by rescoring the MM-GBSA function. This indicates a change in binding free energies of the protein-receptor complex as well as confirms docking accuracy and binding affinities.

Table 3. Binding free energy, docking score, no of the hydrogen bond, and associated amino acids of best three

\begin{tabular}{|c|c|c|c|c|c|c|c|c|c|c|c|c|c|}
\hline \multirow{2}{*}{$\begin{array}{l}\text { Pub } \\
\text { Che } \\
\text { m } \\
\text { ID }\end{array}$} & \multirow{2}{*}{$\begin{array}{l}\text { Ligan } \\
\text { d }\end{array}$} & \multicolumn{3}{|c|}{$\begin{array}{l}\text { Prime } \\
\text { MM-GBSA }\end{array}$} & \multicolumn{3}{|c|}{ Docking Score } & \multicolumn{3}{|c|}{ No. of $\mathrm{HB}$} & \multicolumn{3}{|c|}{ H-bond Interactive Residues } \\
\hline & & $\begin{array}{l}\text { 6W4 } \\
\text { H }\end{array}$ & $\begin{array}{l}6 \mathrm{W6} \\
3 \\
\end{array}$ & $\begin{array}{l}6 \mathrm{~V} \\
\text { YO }\end{array}$ & $\begin{array}{l}\text { 6W4 } \\
\text { H }\end{array}$ & $\begin{array}{l}6 \mathrm{W6} \\
3\end{array}$ & $\begin{array}{l}6 \mathrm{~V} \\
\text { YO }\end{array}$ & $\begin{array}{l}6 \mathrm{6W} \\
4 \mathrm{H}\end{array}$ & $\begin{array}{l}6 W \\
63\end{array}$ & $\begin{array}{l}6 \mathrm{~V} \\
\text { YO }\end{array}$ & $6 \mathrm{~W} 4 \mathrm{H}$ & $6 \mathrm{W63}$ & 6VYO \\
\hline $\begin{array}{l}7151 \\
5458\end{array}$ & $\begin{array}{l}\text { Plazo } \\
\text { micin }\end{array}$ & $\begin{array}{l}- \\
47.35 \\
6\end{array}$ & $\begin{array}{l}- \\
46.07 \\
5\end{array}$ & & $\begin{array}{l}- \\
13.09 \\
9\end{array}$ & - & - & 8 & 5 & - & $\begin{array}{l}\text { ASA687 } \\
0 \\
\text { GLY687 } \\
9 \\
\text { TYR693 } \\
0 \\
\text { ASP691 } \\
2 \\
\text { GLY686 } \\
9 \\
\text { ASP692 } \\
8 \\
\text { ASP693 } \\
1 \\
\text { ASP689 } \\
7\end{array}$ & $\begin{array}{l}\text { PHE14 } \\
0 \\
\text { HIE164 } \\
\text { GLU- } \\
166 \text { (3) }\end{array}$ & - \\
\hline $\begin{array}{l}7784 \\
3966\end{array}$ & $\begin{array}{l}\text { Cefide } \\
\text { rocol }\end{array}$ & $\begin{array}{l}- \\
49.51 \\
7\end{array}$ & $\begin{array}{l}- \\
69.39 \\
2\end{array}$ & & $\begin{array}{l}- \\
11.25 \\
6\end{array}$ & - & - & 8 & 6 & - & $\begin{array}{l}\text { ASN699 } \\
6 \\
\text { ASP692 } \\
8 \\
\text { GLY686 } \\
9 \\
\text { ASP691 } \\
2\end{array}$ & $\begin{array}{l}\text { GLN18 } \\
9 \\
\text { THR19 } \\
0 \\
\text { GLY14 } \\
3 \\
\text { ARG18 } \\
8 \\
\text { THR25 } \\
\text { ASN11 } \\
9 \\
\end{array}$ & - \\
\hline $\begin{array}{l}1354 \\
1353 \\
4\end{array}$ & $\begin{array}{l}\text { Valgan } \\
\text { ciclovi } \\
\mathrm{r}\end{array}$ & $\begin{array}{l}- \\
45.59 \\
0\end{array}$ & - & $\begin{array}{l}- \\
48.0 \\
5\end{array}$ & -9.9 & - & $\overline{8} .02$ & 4 & & 6 & $\begin{array}{l}\text { ASP692 } \\
8 \\
\text { TYR693 } \\
0 \\
\text { LYS696 } \\
8 \\
\text { CYS691 } \\
3\end{array}$ & - & $\begin{array}{l}\text { Chain-- } \\
\text { C: } \\
\text { ALA55 } \\
\text { Chain-D: } \\
\text { ASN75 } \\
\text { ASN77 } \\
\text { ASN154 }\end{array}$ \\
\hline
\end{tabular}

3.4. Molecular docking and potential ligands characteristics of 6w63, 6w4h and 6vyo.

Out of 265 drugs, the best three drugs were sorted on the basis of their ligand binding affinity (free energy values), docking scores, number of hydrogen bonds, and interactive residues. We have found that these three-drug molecules have the best docking scores as well as great interaction against all targets. Tables 3 shows the prime MM-GBSA free energies, Docking scores, number of hydrogen bonds, and hydrogen bond interactive amino acid residues of $6 \mathrm{w} 4 \mathrm{~h}, 6 \mathrm{w} 63$, and 6vyo, respectively. Each of the final drugs has shown interaction with two proteins simultaneously, which explores the possibility of their use as dual inhibitors. 
The Plazomicin and Cefiderocol have shown interactions together with $6 \mathrm{w} 4 \mathrm{~h}$ and 6w63. However, the Valganciclovir has shown interaction with $6 \mathrm{w} 4 \mathrm{~h}$ and 6vyo. The computational parameters for Plazomicin and the two protein interactions are remarkable. These protein-ligand complexes show docking scores of -13.10 and -7.53, binding free energies ( $\Delta$ Gbind) of $-47.35 \mathrm{kcal} / \mathrm{mol}$ and $-46.07 \mathrm{kcal} / \mathrm{mol}$, and hydrogen bond interactions of 8 and 5 for $6 \mathrm{w} 4 \mathrm{~h}$ and $6 \mathrm{w} 63$, respectively. The Cefederocol is the second compound that has relatively similar virtual statistics as the previous antibiotics, and even interactions are with the same two proteins. These complexes have docking scores of -11.26 and -7.87 , binding free energies ( $\Delta$ Gbind) of $-49.52 \mathrm{kcal} / \mathrm{mol}$ and $-69.39 \mathrm{kcal} / \mathrm{mol}$, and hydrogen bond interactions of 8 and 6 for 6w4h and 6w63, respectively.

Additionally, we can appreciate the less negative values of docking and binding free energy for Vanganciclovir in table 3 interacting with a separate set of proteins such as $6 \mathrm{w} 4 \mathrm{~h}$ and 6vyo. Here the docking score of -9.90 and $-8.02, \Delta$ Gbind of -45.59 and -48.05 , number of hydrogen bonds interactions of 4 and 6 are seen respectively. The comparison of docking scores and MM-GBSA values of the best three drug molecules presented in Figs. 3, 4 (docking score) in which it has been found that the drug showed the high docking as well as MM/GBSA values common to all three proteins.

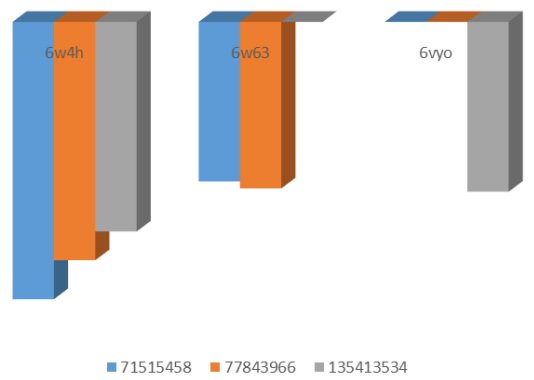

Figure 3. Docking score of best three ligands against 6w4h, 6w63, and 6vyo.

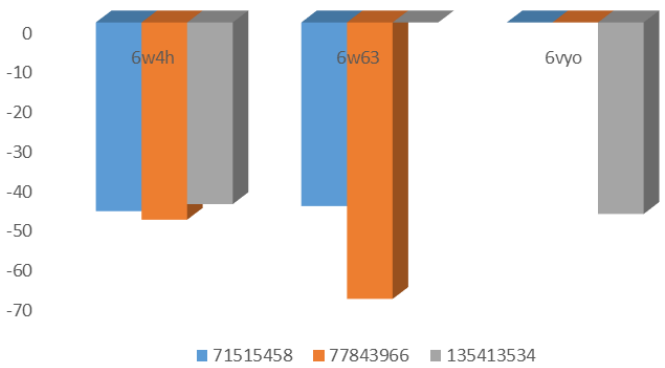

Figure 4. Binding free energy (MM-GBSA values) of best three ligands against 6w4h, 6w63, and 6vyo.

These three drugs depict reliable interaction with amino acid residues of NSP6, main protease, and $\mathrm{N}$-protein. The number of hydrogen bonds and residues acts as a driving force for the precise binding of the ligand to its receptor. For all the three targets, chemical interactions, as well as potential binding of a ligand to its receptor, are presented pictorially in (Fig. 5, 6).

\subsection{Molecular dynamics simulation.}

The molecular dynamics studies were done for drug molecules showing notable docking and binding free energy values. The simulation was carried out for a period of $30000 \mathrm{ps}$ with equilibration for temperature and pressure for Plazomicin. 


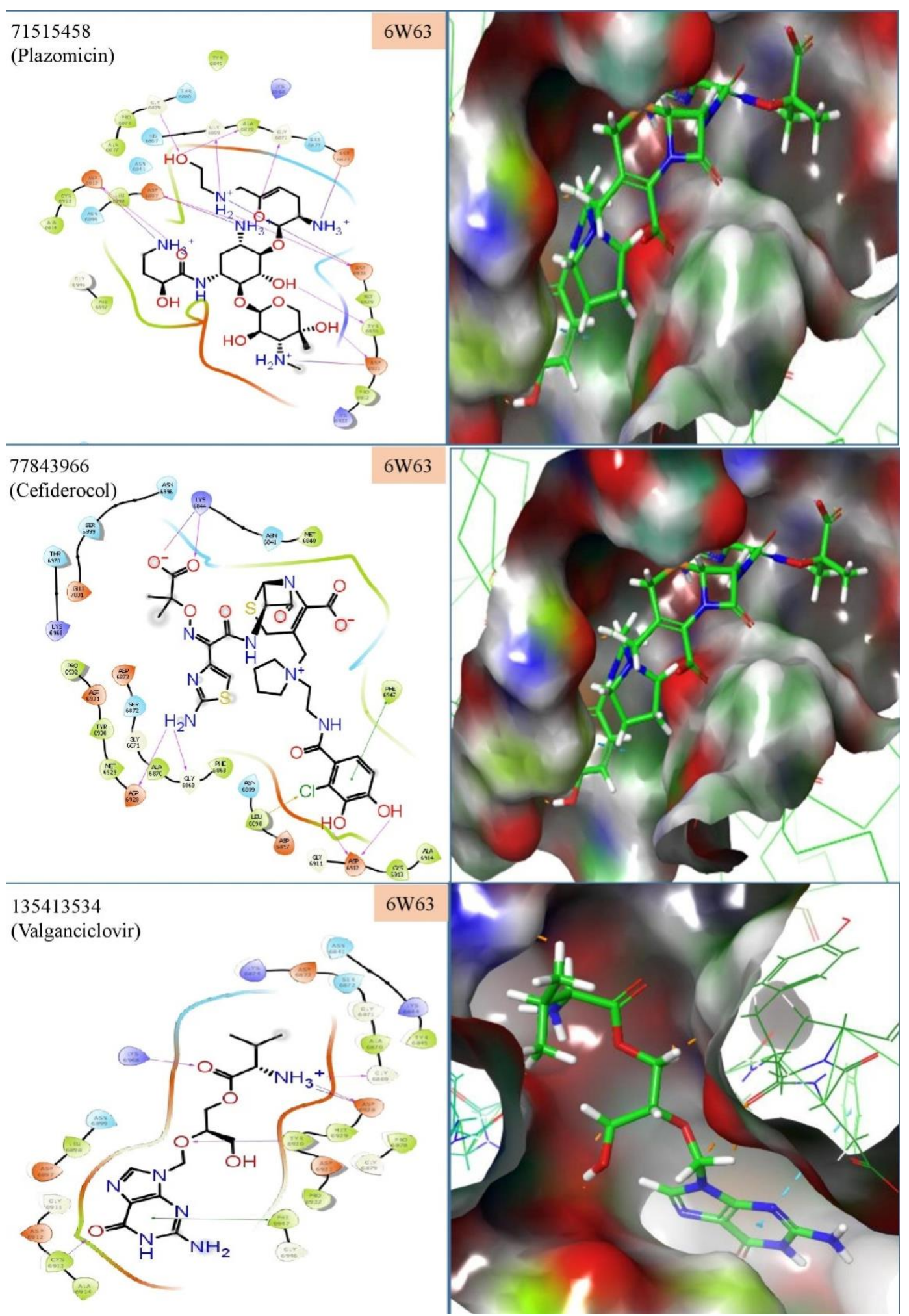

Figure 5. Binding mode and chemical interactions of lead molecules with residues at the active site of $6 \mathrm{w} 4 \mathrm{~h}$ are depicted through Schrodinger software.

The RMSD (root mean square deviation), RMSF (root mean square fluctuation), potential energy, and H-bonds were calculated for checking the stability of ligand-protein complexes. The ligand-protein complex formed at the 10000ps time period and remains stable until the 30000ps period. The RMSD of $0.3 \mathrm{~nm}$ for protein backbone during 20000ps to 30000ps shows the stability of the protein-ligand complex (Fig. 7). 


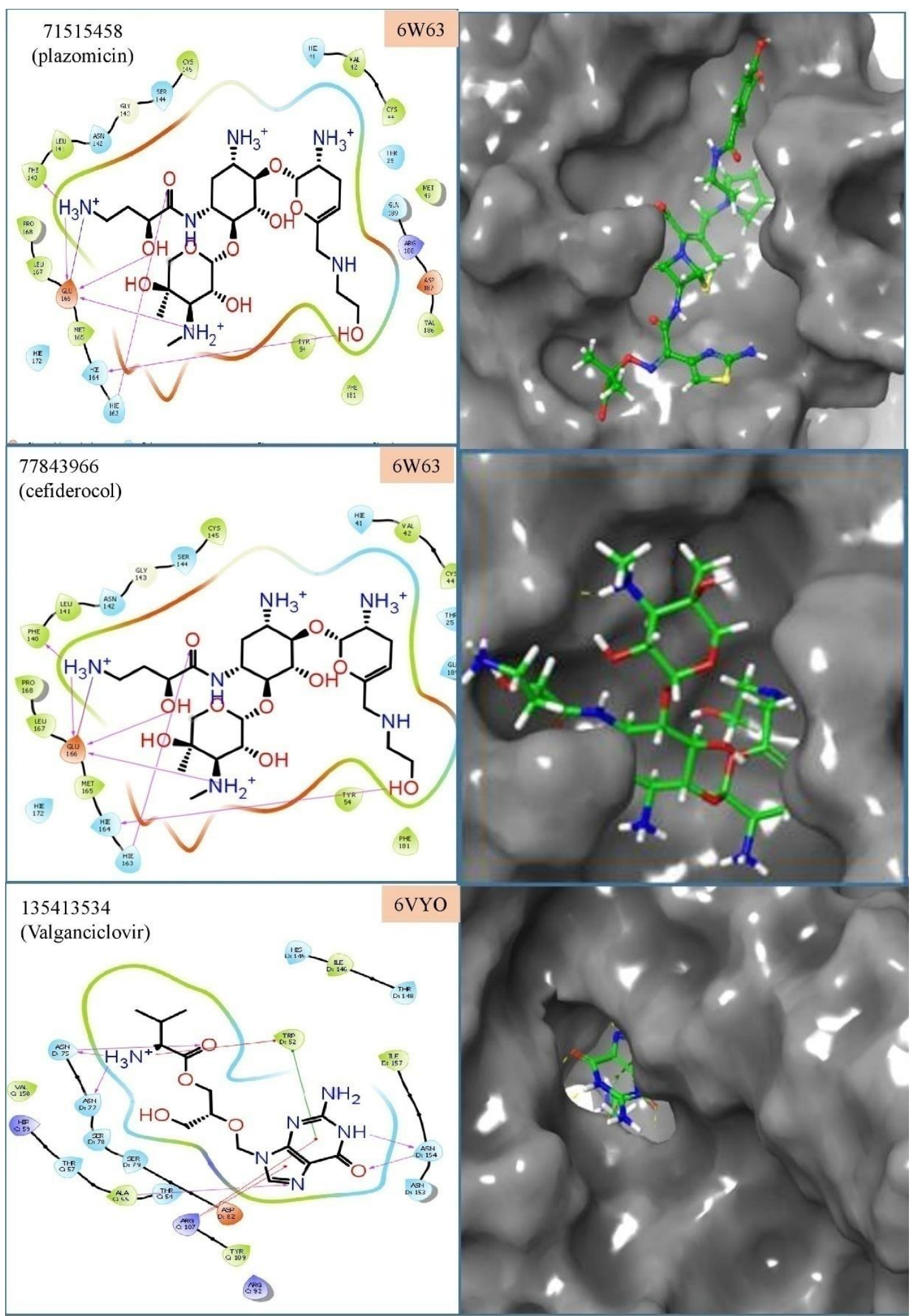

Figure 6. Binding mode and chemical interactions of lead molecules with residues at the active site of $6 \mathrm{w} 63$ and 6vyo are depicted through Schrodinger software.

The RMSF for residues of both the protein chains shows the residues remain stable during the complex formation (Fig. 7). And the potential energy of the system is stable throughout the simulation period (Fig. 8). The complex is supported by 2 hydrogen bonds (on average) throughout the simulation period (Fig. 8). The simulation results provide support for protein-ligand complex stability. 

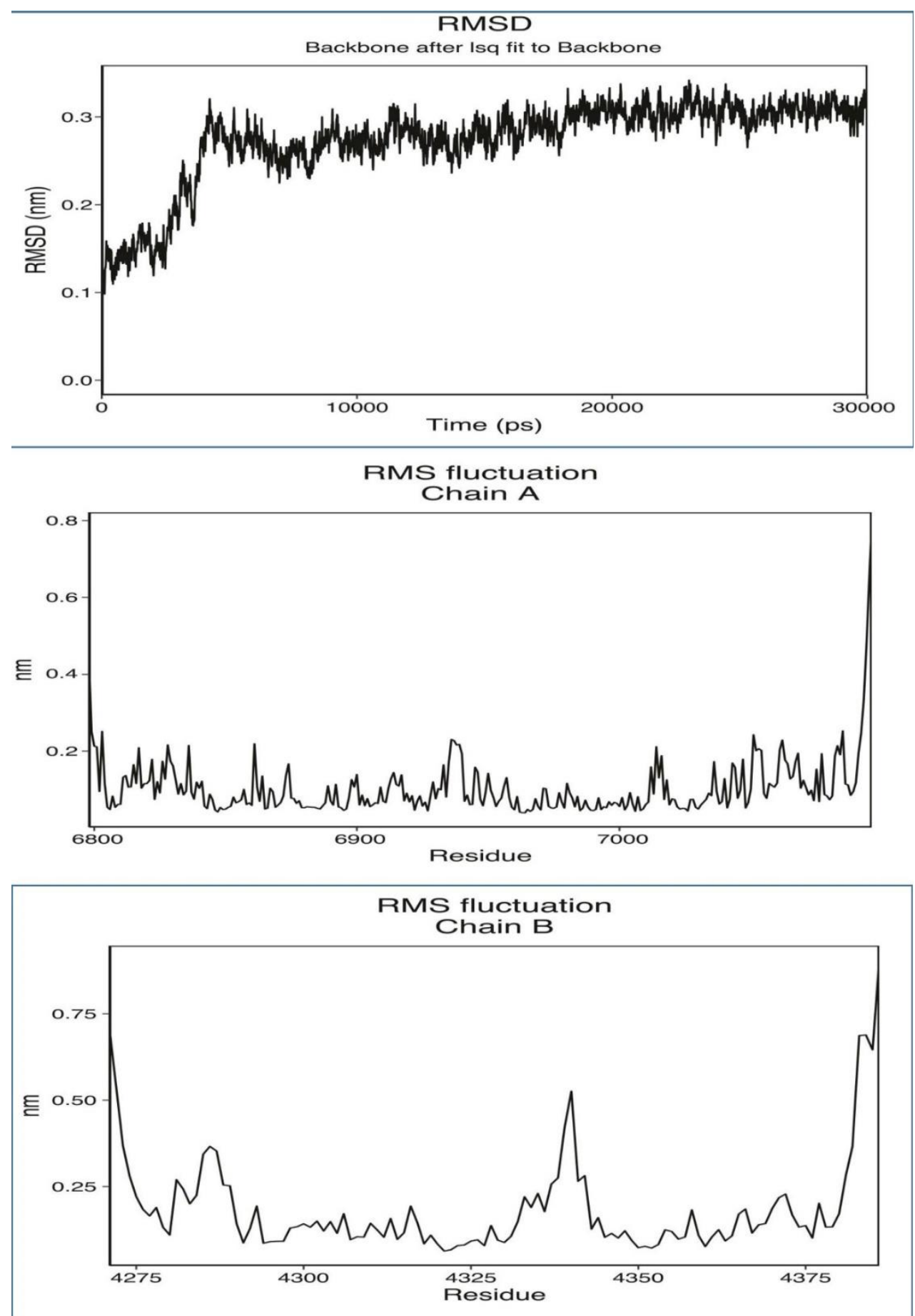

Figure 7. Molecular Dynamics Simulation (MDS) results of ligand-protein complex for30ns. A: Root Mean Square Deviation of ligand-protein complex; B \& C: Root Mean Square Fluctuation (RMSF) of chain-A and B, respectively.

\subsection{Biological activity of the best drugs.}

The final three drugs in our study belonged to two main categories. The Plazomicin (Aminoglycoside) and Cefiderocol (Cephalosporins) are an antibiotic group of drugs (Table 4). The Vanganciclovir is presently used against Cytomegalovirus in HIV/AIDS patients. These drugs have shown the potential to become the dual inhibitors against two targets of the SARS-CoV-2 [30]. These ligands have shown a good docking score and acceptable binding energy against all the three Covid-19 targets. 

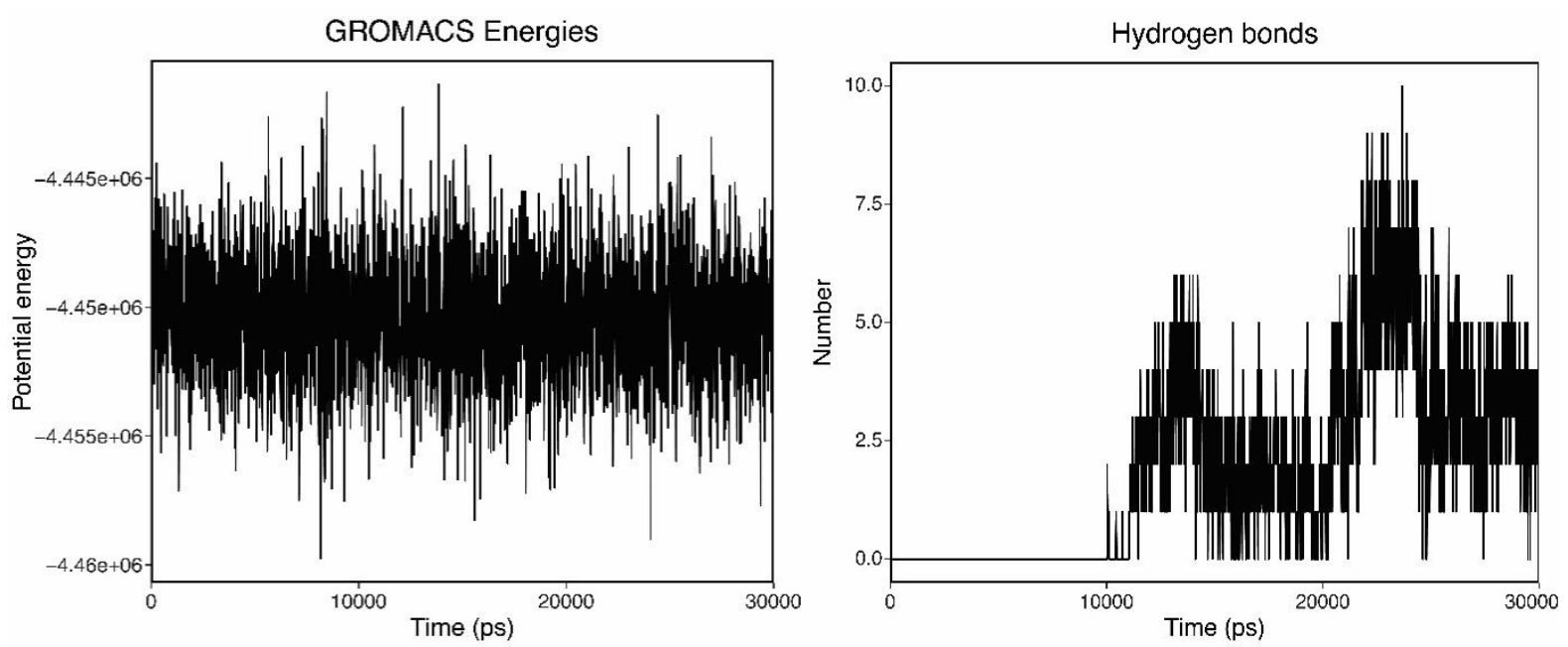

Figure 8. Molecular Dynamics Simulation (MDS) results of the ligand-protein complex for 30ns.

The use of these ligands may inhibit the 3C-like proteinase along with non-structural protein 16 (NSP16) or 3C-like proteinase along with Nucleocapsid proteins (N protein), which may be a doorway to form novel drugs against the deadly coronavirus COVID-19 pandemic which is much needed to save human race on earth.

Table 4. Potential three FDA approved drugs and their biological activities.

\begin{tabular}{l|l|l|l} 
Drug & Name of drug & Indication & Mechanism of Action \\
\hline 71515458 & Plazomicin & $\begin{array}{l}\text { Complicated } \\
\text { Urinary Tract } \\
\text { Infections (UTI) } \\
{[31]}\end{array}$ & $\begin{array}{l}\text { Bactericidal action by binding to the 30S ribosomal unit of } \\
\text { the bacteria. https://www.drugbank.ca/drugs/DB12615. }\end{array}$ \\
\hline 77843966 & Cefiderocol & Also used in UTI & $\begin{array}{l}\text { Inhibit Cell Wall synthesis by binding to Penicillin's } \\
\text { binding } \\
\text { https://www.drugbank.ca/drugs/DB14879. }\end{array}$ \\
\hline 135413534 & Valganciclovir & $\begin{array}{l}\text { Cytomegalovirus } \\
(\mathrm{CMV}) \text { infection }\end{array}$ & $\begin{array}{l}\text { Viral DNA synthesis inhibition by producing active } \\
\text { ganciclovir. https://www.drugbank.ca/drugs/DB01610 }\end{array}$
\end{tabular}

\section{Conclusions}

Computer-assisted functional and structural insights into FDA approved drug for infectious diseases group in PubChem database showed good docking scores, bonding affinities, and hits against all the three SARS-CoV-2 targets, i.e., 6w63, 6w4h, and 6vyo. The Plazomicin, an aminoglycoside, and Cefiderocol, cephalosporins, are the antibiotic group of drugs. These two antibacterial drugs (Cefiderocol and Plazomicin) show great dual inhibitor potential against targets of Covid-19 (main protease and NSP16). And one antiviral drug Vanganciclovir approved for CMV infection in HIV patients, has shown activity against (Main Protease and N protein). We suggest these ligands can be novel drug prospects for COVID-19 as dual inhibitors. These ligands, individually or in combination, can be taken forward for the development of new drugs against novel SARS-CoV-2.

\section{Funding}

This research received no external funding.

\section{Acknowledgments}

The authors are thankful to Dr. Prajwal Nandekar, Mr. Vinod Devaraji, and Ms. Shelvia Malik of Schrodinger, Bengaluru, India, for their kind help. 


\section{Conflicts of Interest}

\section{The authors declare no conflict of interest.}

\section{References}

1. Zheng, J. SARS-CoV-2: An emerging coronavirus that causes a global threat. Int. J. Biol. Sci. 2020, 16, 1678-1685, https://doi.org/10.7150/ijbs.45053.

2. Dan, S.; Pant, M.; Upadhyay, S.K. The case fatality rate (CFR) in SARS-COV-2 patients with cardiovascular disease (CVD): A global health risk paradigm in COVID-19 pandemic. Curr. Pharmacol. Rep. 2020, https://doi.org/10.1007/s40495-020-00239-0.

3. Mousavizadeh, L.; Ghasemi, S. Genotype and phenotype of COVID-19: Their roles in pathogenesis. J. Microbiol. Immunol. Infect. 2020, 10, https://doi.org/10.1016/j.jmii.2020.03.022.

4. Upadhyay, S.K.; Singh, R.; Babita; Kumar, G.; Singh, G. The outbreak and challenges of novel coronavirus (COVID-19): The global pandemic emergency of early 2K20 and Indian scenario. Int. J. Biol. Pharma. All. Sci. 2020a, 9, 1173-1199, http://doi.org/10.31032/IJBPAS/2020/9.5.5126.

5. Li, H.; Liu, S.M.; Yu, X.H.; Tang, S.L.; Tang, C.K. Coronavirus disease 2019 (COVID-19): Current status and future perspective. Int. J. Antimicro. Agents 2020, 29, http://doi.org/10.1016/j.ijantimicag.2020.105951.

6. Shereen, M.A.; Khan, S.; Kazmi, A.; Bashir, N.; Siddique, R. COVID-19 infection: Origin, transmission, and characteristics of human coronaviruses. J. Adv. Res. 2020, 91-98, http://doi.org/10.1016/j.jare.2020.03.005.

7. Sood, S.; Aggarwal, V.; Aggarwal, D.; Upadhyay, S.K.; Sak, K.; Tuli, H.S.; Kumar, M.; Kumar, J.; Talwar, S. Covid-19 pandemic: From molecular biology, pathogenesis, detection and treatment to global societal impact. Curr. Pharma. Rep. 2020, 6, 212-227, http://doi.org/10.1007/s40495-020-00229-2.

8. Pal, M.; Berhanu, G.; Desalegn, C.; Kandi, V. Severe acute respiratory syndrome Coronavirus-2 (SARSCoV-2): An update. Cureus 2020, 12, http://doi.org/10.7759/cureus.7423.

9. Méndez, E.; Salas-Ocampo, M.E.; Munguía, M.E.; Arias, C.F. Protein products of the open reading frames encoding non-structural proteins of human astrovirus serotype 8. J. Virol. 2003, 77, 11378-11384, http://doi.org/10.1128/jvi.77.21.11378-11384.2003.

10. Chen, B.; Tian, E.K.; He, B.; Tian, L.; Han, R.; Wang, S.; Xiang, Q.; Zhang, S.; El Arnaout, T.; Cheng, W.Overview of lethal human coronaviruses. Signal Trans. Target. Ther. 2020, 5, 1-16, http://doi.org/10.1038/s41392-020-0190-2.

11. Upadhyay, S.K.; Singh, R.; Singh, M.; Kumar, V.; Yadav, M.; Aggarwal, D.; Sehrawat, N. COVID-19 in republic of India: A report on situation and precautionary strategies to global pandemic. Bull. Environ. Pharmacol. Life Sci. 2020b, 9, 39-48.

12. Bhardwaj, S.; Tiwari A. Highlights on evidence-based treatment strategies for COVID-19: A review. Lett. Appl. NanoBioSci. 2020, 9, 1359-1371, https://doi.org/10.33263/LIANBS93.13591371.

13. Kang, S.; Yang, M.; Hong, Z.; Zhang, L.; Huang, Z.; Chen, X.; Yan, Y. Crystal structure of SARS-CoV2 nucleocapsid protein RNA binding domain reveals potential unique drug targeting sites. Acta Pharma. Sin. B.2020, https://doi.org/10.1101/2020.03.06.977876.

14. Zehra, Z.; Luthra, M.; Siddiqui, S. M.; Shamsi, A.; Gaur, N.; Islam, A. Corona virus versus existence of human on the earth: A computational and biophysical approach. Int. J. Biol. Macromol. 2020, 161, 271-281, https://doi.org/10.1016/j.ijbiomac.2020.06.007.

15. Barretto, N.; Jukneliene, D.; Ratia, K.; Chen, Z.; Mesecar, A.D.; Baker, S.C. The papain-like protease of severe acute respiratory syndrome coronavirus has deubiquitinating activity. J. Virol. 2005, 79, 1518915198, https://doi.org/10.1128/jvi.79.24.15189-15198.2005.

16. Hosny, N.M.; Sherif, Y. Molecular docking study on some isonicotinoyl hydrazide derivatives as potential inhibitors of COVID-19. Lett. Appl. NanoBioSci. 2020, 9, 1217-1224, https://doi.org/10.33263/LIANBS93.12171224.

17. Neuvonen, M.; Ahola, T. Differential activities of cellular and viral macro domain proteins in binding of ADP-ribose metabolites. J. Mol. Biol. 2009, 385, 212-225, https://doi.org/10.1016/j.jmb.2008.10.045.

18. Shannon, A.; Le, N.T.T.; Selisko, B.; Eydoux, C.; Alvarez, K.; Guillemot, J.C.; Canard, B. Remdesivir and SARS-CoV-2: Structural requirements at both nsp12 RdRp and NSP14 Exonuclease active-sites. Antivir. Res. 2020, 178, https://doi.org/10.1016/j.antiviral.2020.104793.

19. Snijder, E.J.; Decroly, E.; Ziebuhr, J. The non-structural proteins directing coronavirus RNA synthesis and processing. Adv. Virus Res. 2016, 96, 59-126, https://doi.org/10.1016/bs.aivir.2016.08.008.

20. Astuti, I.; Ysrafil. Severe acute respiratory syndrome coronavirus 2 (SARS-CoV-2): An overview of viral structure and host response- Diabetes and metabolic syndrome. Clin. Res. Rev. 2020, 14, 407-412, https://doi.org/10.1016/j.dsx.2020.04.020.

21. Chen, Y.; Su, C.; Ke, M.; Jin, X.; Xu, L.; Zhang, Z.; Ahola, T. Biochemical and structural insights into the mechanisms of SARS coronavirus RNA ribose 2'-O-methylation by nsp16/nsp10 protein complex. PLoS Patho. 2011, 7, https://doi.org/10.1371/journal.ppat.1002294. 
22. Decroly, E.; Debarnot, C.; Ferron, F.; Bouvet, M.; Coutard, B.; Imbert, I.; Ortiz-Lombardia, M. Crystal structure and functional analysis of the SARS-coronavirus RNA cap 2'-O-methyltransferase nsp10/nsp16 complex. PLoS Patho. 2011, 7, https://doi.org/10.1371/journal.ppat.1002059.

23. Joob, B.; Wiwanitkit, V. Nanodiagnosis for diagnosing COVID-19: A brief review. Lett. Appl. NanoBioSci. 2020, 9, 1578-1582, https://doi.org/10.33263/LIANBS94.15781582.

24. Romano, M.; Ruggiero, A.; Squeglia, F.; Maga, G.; Berisio, R. A Structural view of SARS-CoV-2 RNA replication machinery: RNA synthesis, proofreading and final capping. Cells 2020, 9, https://doi.org/10.3390/cells9051267.

25. Encinar, J.A.; Menendez, J.A. Potential drugs targeting early innate immune evasion of sars-coronavirus 2 via 2'-O-methylation of viral RNA. Viruses 2020, 12.

26. Wang, Y.; Sun, Y.; Wu, A.; Xu, S.; Pan, R.; Zeng, C.; Chen, Y. Coronavirus NSP10/NSP16 methyltransferase can be targeted by nsp10-derived peptide in vitro and in vivo to reduce replication and pathogenesis. J. Virol. 2015, 89, 8416-8427, https://doi.org/10.1128/jvi.00948-15.

27. Belsham, G.J.; Nielsen, I.; Normann, P.; Royall, E.; Roberts, L.O. Monocistronic mRNAs containing defective hepatitis $\mathrm{C}$ virus-like picornavirus internal ribosome entry site elements in their $5^{\prime}$ untranslated regions are efficiently translated in cells by a cap-dependent mechanism. RNA 2008, 14, 1671-1680 , https://doi.org/10.1261/rna.1039708.

28. Aouadi, W.; Blanjoie, A.; Vasseur, J.J.; Debart, F.; Canard, B.; Decroly, E. Binding of the methyl donor Sadenosyl-1-methionine to Middle East respiratory syndrome coronavirus 2'-O-methyltransferase NSP16 promotes recruitment of the allosteric activator NSP10. J. Virol. 2017, 91, 2217-2233, https://doi.org/10.1128/jvi.02217-16.

29. Dwivedi, P.; Tiwary, D.; Narvi, S.S.; Tewari, R.P.; Shukla, K.P. Curcuma longa aided Ag/CS nanocomposite coating of surfaces as SARS-CoV-2 contamination minimizing measure towards containment of COVID-19: A perspective. Lett. Appl. NanoBioSci. 2020, 9, 1485-1493, https://doi.org/10.33263/LIANBS94.14851493.

30. World Health Organization. WHO declares the coronavirus outbreak a global pandemic. https://www.cnbc.com/2020/03/11/who-declares-the-coronavirus-outbreak-a-global-pandemic.html (Accessed: 18 July 2020).

31. Singh, R.; Upadhyay, S.K.; Singh, M.; Yadav, M.; Kumar, V.; Sehrawat, N. A report on antibiotic susceptibility and resistance of pathogens causing urinary tract infection (UTI) to human patients. Bull. Pure Appl. Sci. Zool. 2019, 38A, 170-176, https://doi.org/10.5958/2320-3188.2019.00020.2. 